\title{
X-1: THE CHALLENGE OF HIGH FUSION YIELD*
}

D. L. Cook, J. J. Ramirez, P. S. Raglin, G. E. Rochau, M. K. Matzen, R. J. Leeper, J. L. Porter, R. E. Olson, D. H. McDaniel, R. B. Spielman, C. Deeney, and J. P. Quintenz Sandia National Laboratories Albuquerque, NM 87185-1190

\author{
R. R. Peterson \\ University of Wisconsin \\ Madison, WI 53706
}

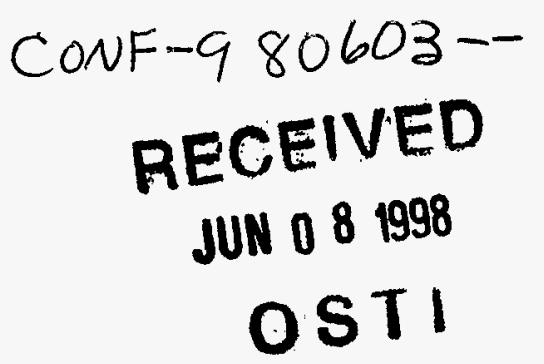

\section{ABSTRACT}

In the past three years, tremendous strides have been made in $\mathrm{x}$-ray production using highcurrent $z$-pinches ${ }^{1-5}$. Today, the $\mathrm{x}$-ray energy and power output of the $\mathrm{Z}$ accelerator ${ }^{6}$ (formerly PBFA II) is the largest available in the laboratory. These $z$-pinch $x$-ray sources have great potential to drive high-yield inertial confinement fusion (ICF) reactions at affordable cost if several challenging technical problems can be overcome. Technical challenges in three key areas are discussed in this paper: the design of a target for high yield, the development of a suitable pulsed power driver, and the design of a target chamber capable of containing the high fusion yield.

\section{INTRODUCTION}

The $\mathrm{Z}$ accelerator at Sandia National Laboratories now produces a peak x-ray output energy of $1.8 \mathrm{MJ}$ and a peak x-ray output power of $280 \mathrm{TW}$ from a z-pinch driven at approximately 20 MA. Optimization of z-pinch behavior on the $\mathrm{Z}$ accelerator and three prior generations of accelerators (Saturn at $10 \mathrm{MA}$, Proto II at $5 \mathrm{MA}$, and SuperMite at $1.5 \mathrm{MA}$ ) has shown that the $\mathrm{x}$ ray energy output from high-current z-pinches scales quadratically with z-pinch current. This scaling is in agreement with simple zero-dimensional analytic theory. For fixed output pulse width, the $\mathrm{x}$-ray power also scales quadratically with current. When the z-pinch is used to drive a hohlraum, the hohlraum radiation $\left(\sigma \mathrm{T}^{4}\right)$ is proportional to the z-pinch source radiation $\left(\mathrm{I}^{2}\right)$, and the hohlraum temperature is proportional to the square root of the z-pinch current. These basic relationships, demonstrated conclusively on the $Z$ accelerator, indicate that a single accelerator with about three times the current of $Z$ (or about $60 \mathrm{MA}$ ), or two accelerators, each having about twice the current of $Z$ (or about $40 \mathrm{MA}$ ), should be sufficient to drive a fusion capsule to high fusion yield. The features of this accelerator, called X-1, are discussed in this paper. It is a remarkable result that the energy conversion efficiency, from electrical energy stored in the Marx generator to x-ray energy produced in a short pulse by a fast z-pinch, exceeds $15 \%$ on the $Z$ accelerator. The implications of this result are that sufficient $\mathrm{x}$-ray energy can be produced at modest cost in X-1 to drive an ICF capsule to high yield.

*Sandia is a multiprogram laboratory operated by Sandia Corporation, a Lockheed Martin Company, for the United States Department of Energy under Contract DE-AC04-94AL85000 


\section{DISCLAIMER}

This report was prepared as an account of work sponsored by an agency of the United States Government. Neither the United States Government nor any agency thereof, nor any of their employees, makes any warranty, express or implied, or assumes any legal liability or responsibility for the accuracy, completeness, or usefulness of any information, apparatus, product, or process disclosed, or represents that its use would not infringe privately owned rights. Reference herein to any specific commercial product, process, or service by trade name, trademark, manufacturer, or otherwise does not necessarily constitute or imply its endorsement, recommendation, or favoring by the United States Government or any agency thereof. The views and opinions of authors expressed herein do not necessarily state or reflect those of the United States Government or any agency thereof. 


\section{REQUIREMENTS FOR HIGH YIELD}

The capsule design criteria for high fusion yield come from multi-dimensional target calculations. With an x-ray energy greater than $10 \mathrm{MJ}$, x-ray power greater than $1000 \mathrm{TW}$, hohlraum temperature greater than $225 \mathrm{eV}$, radiation asymmetry smaller than $1-2 \%$, and a temporal pressure profile at the capsule ablation surface appropriate for nearly isentropic compression of cryogenic fusion fuel, calculations give yields in the range of $200-1200 \mathrm{MJ}$. The X-1 facility, which is being explored at the pre-conceptual level now, will be designed to produce $16 \mathrm{MJ}$ and $1000 \mathrm{TW}$ of X-rays, and a hohlraum temperature of $300 \mathrm{eV}$. Three ways to provide radiation symmetry are being explored, as depicted in Figure 1. The first approach separates the $\mathrm{x}$-ray source from the fusion capsule by placing a $\mathrm{z}$-pinch $\mathrm{x}$-ray source on each end of a cylindrical hohlraum containing the fusion capsule, much like the existing heavy-ion-driven ICF target designs. In this design (1a), each z-pinch produces radiation when it stagnates on the axis, and the radiation fills a stationary hohlraum containing the fusion capsule. In the second approach ( $1 \mathrm{~b}$ ), the z-pinches strike a central cylinder which is filled with a low- $Z$ gas or foam. The combination of the strike upon the cylinder and the final stagnation of the combined z-pinch and cylinder mass provides a pulse-shaped x-ray input for the ICF hohlraum. In the third approach (1c) a single $\mathrm{z}$-pinch drives a dynamic hohlraum which also contains the fusion capsule inside a density-tailored foam at the interior of the cylindrical, or quasi-spherical, z-pinch. In going from 1a to $1 \mathrm{c}$, the hydrodynamic risk of non-reproducible z-pinch behavior or of a hydrodynamic interaction between the z-pinch(es) and the fusion capsule is increased, but progressively smaller volumes must be heated, and higher drive temperatures become possible. The required time-dependent pressure profile at the capsule ablation surface can be provided by a combination of time-dependent $\mathrm{x}$-ray pulse shaping and pressure tailoring via material layers in the capsule ablator. In order to achieve high yield in an efficient manner (i.e., achieve high gain at the same time), the fusion fuel in the capsule must be initially cryogenic, and the fuel must be compressed to a density of more than 100 times liquid density on an adiabat whose pressure is not more than a factor of about 4 from the Fermi-degenerate value at the same final density.

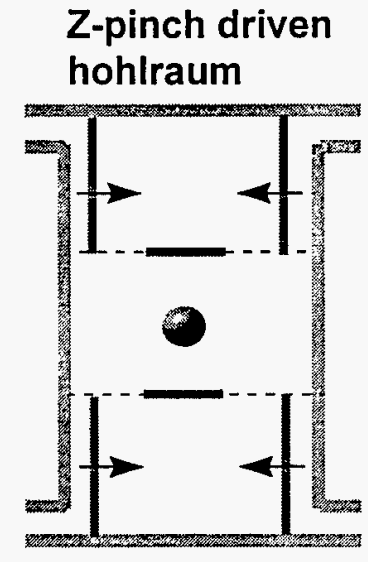

a

\section{Static-walled hohlraum}
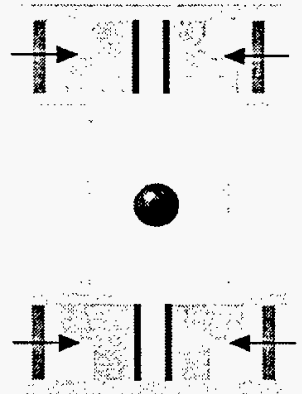

b
Imploding liner hohlraum

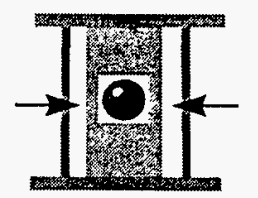

c

Figure 1. Three target configurations for high fusion yield. 


\section{PULSED POWER DRIVER}

The pulsed power driver for X-1 consists of four basic sections: the energy storage section, the dielectric pulse forming section, the power transition section, and the vacuum power flow section. Several alternative design options are being evaluated in a pre-conceptual design study. A representative sketch for a driver topology similar to that of the Saturn and Z accelerators is shown in Figure 2. In the particular design shown, there are 144 Marx generators, 288 dielectric pulse forming lines, a single centrally located vacuum insulator stack, and a six-feed conically shaped vacuum power flow section.

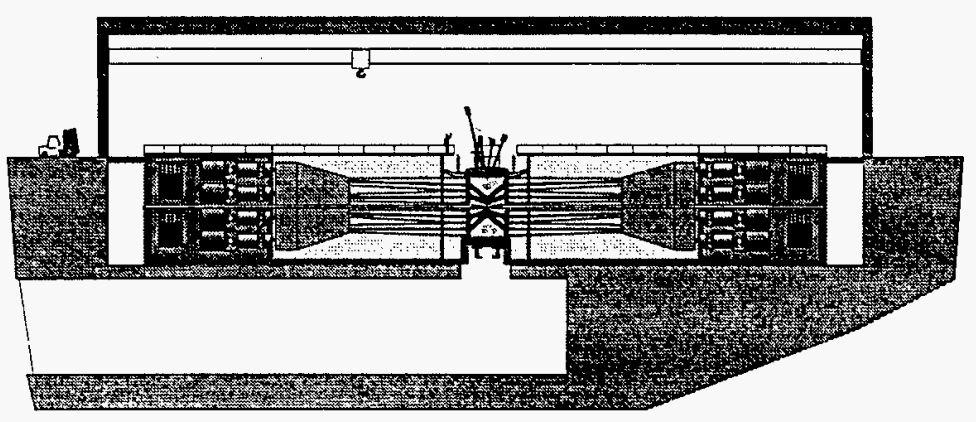

Figure 2. A representative sketch of the pulsed power driver for $\mathrm{X}-1$

Efficient flow of electromagnetic power in vacuum is a major challenge in the X-1 design. Even with no ICF capsule being driven, the magnetic pressure produced by the flow of a $60 \mathrm{MA}$ current to a $10 \mathrm{nH} \mathrm{z}$-pinch will be in the Mbar range. Sustaining an open channel for this electrical power for 100-200 ns through anode-cathode gaps in the range of 2-5 $\mathrm{mm}$ in the presence of radiation from the imploding z-pinch is a key technical issue for X-1. Recent experiments on the $\mathrm{Z}$ accelerator with a $1.5 \mathrm{~mm}$ gap, a drive time of $110 \mathrm{~ns}$, and a current per unit length $(\mathrm{I} / 2 \pi \mathrm{r})$ of about $2.4 \mathrm{MA} / \mathrm{cm}$ have been very successful, but these results have not yet been scaled to the level required for X-1 $(5-8 \mathrm{MA} / \mathrm{cm})$. In addition, other recently obtained data from experiments on the Saturn accelerator indicate that greater overall efficiencies than $15 \%$ can be achieved by using a longer z-pinch implosion time than $110 \mathrm{~ns}$, but in order to scale these results to $\mathrm{X}-1$, the requirements placed on the power flow channel to remain open will be even more demanding.

\section{YIELD CONTAINMENT}

Containment of the pressure pulse and activated debris produced by a high-yield ICF capsule is a particularly challenging task for X-1. At a yield of $200 \mathrm{MJ}$, with $40 \mathrm{MJ}$ in $\mathrm{x}$-rays, the hydrodynamic pressure pulse will be about four times that produced by the $16 \mathrm{MJ}$ of $\mathrm{x}$-rays from the z-pinch alone. The neutron output of $160 \mathrm{MJ}$ will activate target region hardware, and an important task will be to minimize activation outside this region. A sketch of the target chamber area for $\mathrm{X}-1$ is shown in Figure 3. The final design must include cryogenic target insertion, neutron and $\mathrm{x}$-ray diagnostics, and isolation of activated debris using explosive closures. 


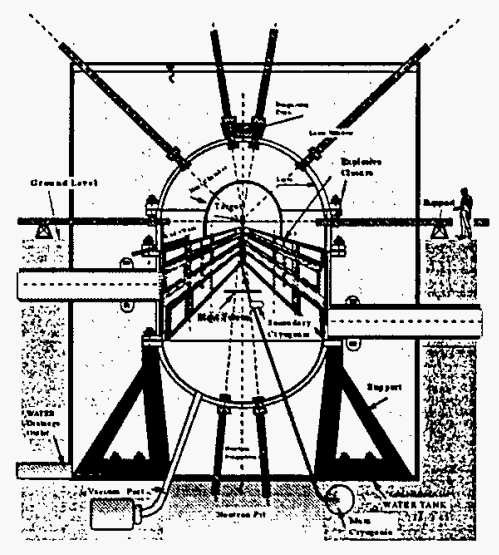

Figure 3. A sketch of the $\mathrm{X}-1$ target chamber area

\section{CONCLUSION}

The successful experiments on the Saturn and $\mathrm{Z}$ accelerators in the past three years have provided new insights into the fundamental behavior of fast high-current z-pinches. The large levels of $\mathrm{x}$-ray energy and $\mathrm{x}$-ray power produced by these z-pinches, and the experimental evidence that their gross behavior follows simple scaling laws, suggests that they may be able to drive fusion capsules to high fusion yield. Preliminary scoping investigations have identified a number of important technical challenges associated with high fusion yield, and the potential solutions to these challenges are motivating further experiments on the Saturn and $\mathrm{Z}$ accelerators, and an increased number of target, accelerator, and yield containment design options for X-1.

\section{ACKNOWLEDGEMENT}

The spectacular technical progress made in fast z-pinches within the past three years using the highest current accelerators, which are located at Sandia, has its origins within several nations and over several decades. Without the persistence of individual researchers involved in pulsed power and in z-pinches over at least the last three decades, and without the free exchange of scientific results as they were developed, the rate of progress would have been substantially slower, and the now encouraging prospects for ultimate achievement of high fusion yield would be considerably poorer.

\section{REFERENCES}

1. T. W. L. Sanford, et al., Phys. Rev. Lett. 77, 5063 (1996).

2. M. K. Matzen, Phys. Plasmas 4, 1519 (1997).

3. T. W. L. Sanford, et al., Rev. Sci. Instrum. 68, 852 (1997).

4. C. Deeney, et al., Rev. Sci. Instrum. 68, 653 (1997).

5. M. R. Douglas, et al., Phys. Rev. Lett. 78, 4577 (1997).

6. R. B. Spielman, et al., Proc. $11^{\text {th }}$ Intl. Conf. on High Power Particle Beams, K. Jungwirth and J. Ullschmied, eds., Prague, Czech Republic, 1996, p. 150. 

Report Number (14) SAND--98-1292C

Publ. Date (11)

Sponsor Code (18)

198806

UC Category (19)

DOE $/ \mathrm{MA}, X F$
UC-900,DOE/ER

19980706084 